\title{
Straddling tricuspid valve without a ventricular septal defect
}

\author{
YUKIHISA ISOMATSU, HIROMI KUROSAWA, YASUHARU IMAI \\ From the Department of Paediatric Cardiovascular Surgery, Heart Institute of Japan, Tokyo Women's \\ Medical College, Tokyo, Japan
}

SUMMARY A four year old girl with pulmonary atresia had a straddling tricuspid valve without an interventricular communication. The overriding tricuspid valve had two orifices, which connected with the right and the left ventricles. Valve tissue separated both orifices and was firmly connected $N$ to the crest of the ventricular septum, thus sealing off the expected interventricular communication. Surgical correction was performed and the outcome was satisfactory.

A straddling tricuspid valve is an infrequent congenital malformation, which by definition is almost always associated with an underlying ventricular septal defect. Recently, however, we have operated on a patient with pulmonary atresia and a straddling tricuspid valve with two separate orifices and no interventricular communication.

\section{Case report}

When the patient was born in May 1982, she weighed $2.6 \mathrm{~kg}$. She showed cyanosis immediately after birth. Non-invasive diagnosis showed pulmonary atresia with intact ventricular septum and a ductus arteriosus. Her condition improved when prostaglandin $E_{1}$ was given. When she was two months old a left Blalock-Taussig shunt and pulmonary valvotomy were performed and when she was four months old an aortopulmonary shunt was performed.

At the age of four years she was admitted for definitive surgical repair. The echocardiogram showed a hypoplastic right ventricle and a tricuspid valve that straddled into the left ventricle (fig 1 ). Preoperative catheterisation showed raised right ventricular pressure $(86 / 7 \mathrm{~mm} \mathrm{Hg})$ caused by residual pulmonary stenosis; the systemic pressure was $98 / 49 \mathrm{~mm} \mathrm{Hg}$. The right ventricular end diastolic volume was $44 \%$ of the expected normal range.

Surgical correction was undertaken. A Glenn

Requests for reprints to Dr Hiromi Kurosawa, Department of Paediatric Cardiovascular Surgery, The Heart Institute of Japan, Tokyo Women's Medical College, 8-1 Kawadacho, Shinjuku-ku, Tokyo, 162 Japan.

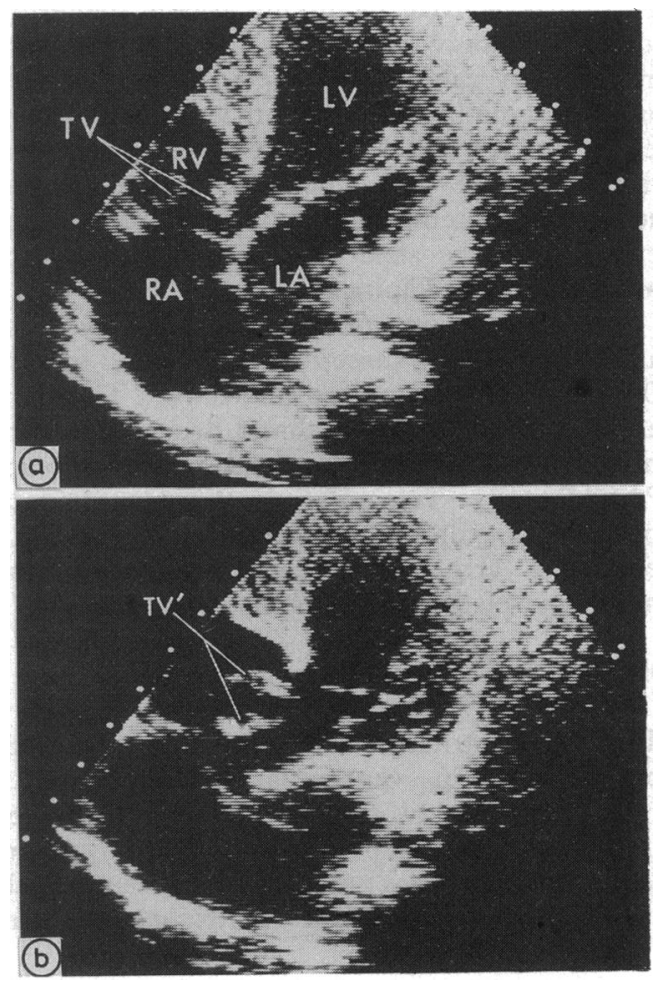

Fig 1 Preoperative echocardiograms. (a) Four chamber view showing a tricuspid valve (TV) connecting the right atrium $(R A)$ to both hypoplastic right ventricle $(R V)$ and left ventricle $(L V)$. (b) Straddling tricuspid valve (TV) opening into left ventricle. $L A$, left atrium. 

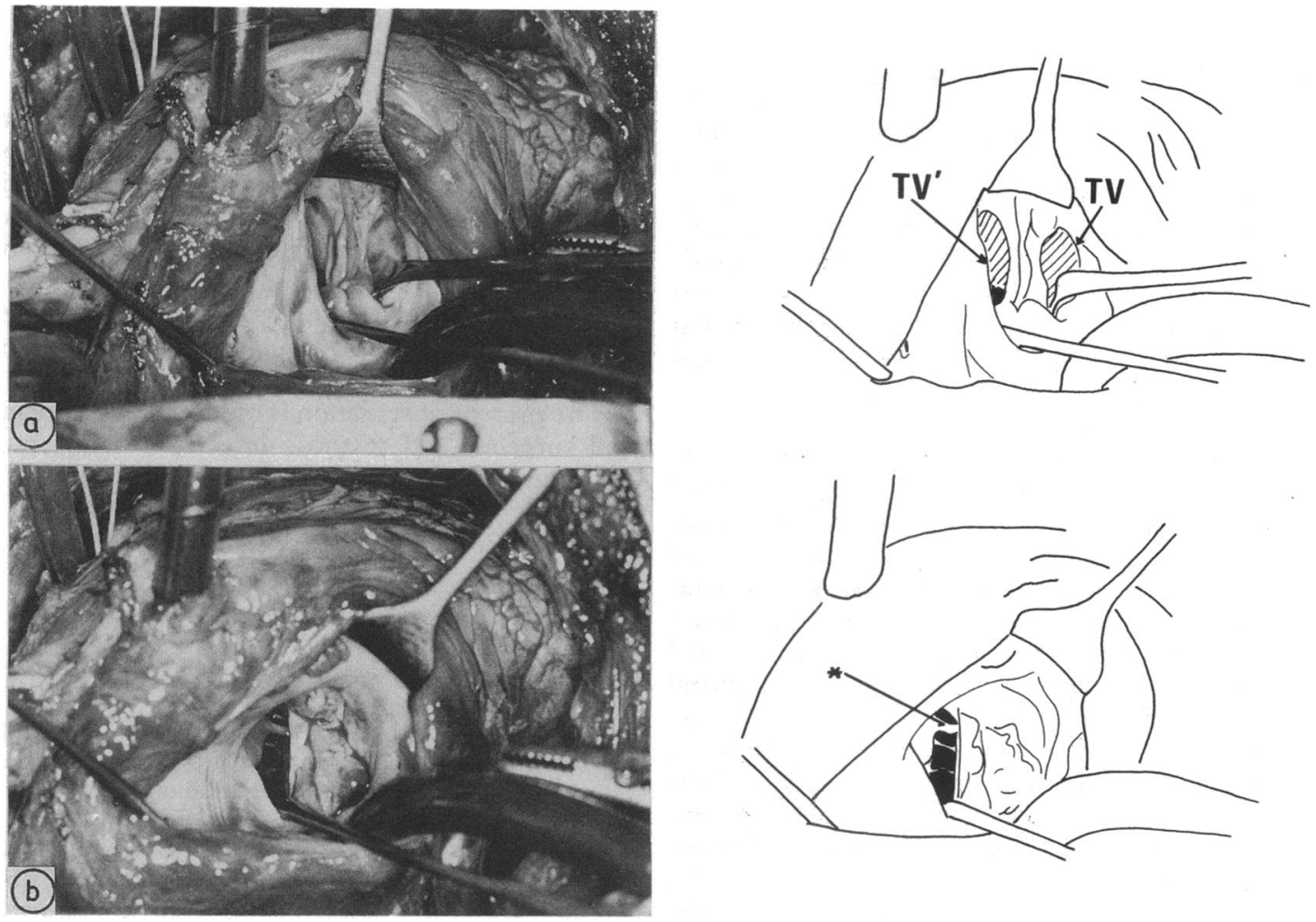

Fig 2 Intraoperative pictures. (a) There are two orifices of the tricuspid valve (TV,TV'). A connecting tongue of fibrous tissue is seen between both orifices. (b) The tension apparatus of the posterior leaflet of the tricuspid valve is inserted into the posterior papillary muscle of the mitral valve $\left({ }^{\star}\right)$.

procedure in which the right pulmonary artery was divided and anastomosed to the superior vena caval vein was performed through a median sternotomy. Pump perfusion was started and the left BlalockTaussig shunt and aortopulmonary shunt were taken down. The tricuspid valve was closely examined through a right atriotomy (fig 2). The diameter of the valve orifice was $27 \mathrm{~mm}$. It overrode the ventricular septum. Approximately two thirds opened into the left ventricle, so that the atrioventricular connection was designated as a double inlet into a left ventricle. The second chamber had right ventricular morphology and was positioned to the right. The inlet part of the ventricular septum did not extend to the crux, but deviated to the right. The anterior leaflet of the straddling portion was devoid of chordae. However, the tension apparatus of the posterior leaflet was inserted into the posterior papillary muscle of the mitral valve. Despite the straddling of the tricuspid valve, there was no interventricular communication because the anterior and posterior parts were connected by valve tissue, itself firmly adherent to the crest of the inlet septum. The arrangement resembled that seen in hearts with an atrioventricular septal defect and two orifices (so called partial variety or ostium primum defect). The ventriculoarterial connection was concordant. In addition, there were associated malformations-for example pulmonary atresia, hypoplastic right ventricle, and atrial septal defect.

The orifice connecting the right atrium to the left ventricle was closed with preserved bovine pericardium. We took care not to injure the atrioventricular node which because of the straddling tricuspid valve was likely to be anomalously sited. Because the remaining right sided tricuspid orifice seemed to be too small to cope with all the inferior venous return we did not ligate the junction between the superior caval vein and the right atrium. The right ventricular outflow tract to the left pulmonary artery was reconstructed with a monocusp patch.

Postoperative catheterisation showed a mean right atrial pressure of $14 \mathrm{~mm} \mathrm{Hg}$ and a mean pulmonary arterial pressure of $13 \mathrm{~mm} \mathrm{Hg}$. She was discharged at 31 days after operation and her condition remains stable. 


\section{Discussion}

A straddling atrioventricular valve can occur as an associated anomaly in various types of congenital heart disease and may cause serious complications, particularly when during surgical correction of the basic deformity. Double outlet right ventricle, complete transposition, congenitally corrected transposition, and double inlet ventricle are well known examples. ${ }^{1-3}$ Almost always there is a large interventricular communication underneath the straddling valve and this usually makes it difficult to close the defect and preserve valve function.

A straddling tricuspid valve without an accompanying ventricular septal defect is extremely rare. ${ }^{4}$ Our patient had an overriding and straddling tricuspid valve with pulmonary atresia, but otherwise normal atrioventricular and ventriculoarterial connections. The tension apparatus of the posterior leaflet of the straddling tricuspid valve was inserted into the posterior papillary muscle of the mitral valve. The potential interventricular communication, however, was closed by a connecting tongue of valve tissue that adhered firmly to the crest of the ventricular septum, as it does in partial atrioventricular septal defects. Thus two ostia were formed. The larger one emptied into the left ventricle and the smaller one led into the right ventricle. The atrioventricular connection was therefore designated as double inlet into a left ventricle.

Indeed, double inlet left ventricle is often complicated by atrioventricular valve malformations, including straddling of the right sided or tricuspid valve. We are unaware, however, of any other reports of patients with such a cardiac malformation, further complicated by pulmonary atresia, in which the interventricular communication underneath the straddling valve was anatomically sealed.

The arrangement may have resulted from incomplete transfer of the inlet component of the developing ventricle. The developing anterior and posterior leaflets of the tricuspid valve may have become fused by the development of valve tissue along the crest of a well developed inlet septum. Thus the connecting tongue may have eventually fused with the ventricular crest, resulting in closure of the interventricular communication before birth.

The present observation is of interest to clinicians and surgeons and to those interested in the morphogenesis of congenital heart malformations.

We thank Professor A E Becker for his advice.

\section{References}

1 Rice MJ, Seward JB, Edwards WD, et al. Straddling atrioventricular valve: two dimensional echocardiographic diagnosis, classification and surgical implications. Am J Cardiol 1985;55:505-13.

2 Tabry IF, McGoon DC, Danielson GK, Wallace RB, Tajik AJ, Seward JB. Surgical management of straddling atrioventricular valve. $J$ Thorac Cardiovasc Surg 1979;77:191-201.

3 Bharati S, McAllister HA Jr, Lev M. Straddling and displaced atrioventricular orifices and valves. Circulation 1979;60:673-84.

4 Anderson RH. Discussion on chapters 34-37. In: Becker AE, Losekoot TG, Marcelletti C, Anderson RH, eds. Paediatric cardiology vol 3. Edinburgh: Churchill Livingstone, 1981:442. 